\title{
Anti-(U1) Small Nuclear RNA Antibodies in Anti-Small Nuclear Ribonucleoprotein Sera from Patients with Connective Tissue Diseases
}

\author{
W. J. van Venrooij," R. Hoet, * J. Castrop,“ B. Hageman, ${ }^{*}$ I. W. Mattaj, ${ }^{\ddagger}$ and L. B. van de Putte \\ Departments of ${ }^{*}$ Biochemistry and ${ }^{\S}$ Rheumatology, University of Nijmegen, 6500 HB Nijmegen, The Netherlands; \\ and ${ }^{\ddagger}$ European Molecular Biology Laboratory, Heidelberg, Federal Republic of Germany
}

\section{Abstract}

Small nuclear ribonucleoprotein (snRNP) particles are a class of RNA-containing particles in the nucleus of eukaryotic cells. Sera from patients with connective tissue diseases often contain antibodies against the proteins present in these snRNPs. Antibodies against the RNA components of snRNPs, the $U$ snRNAs, are thought to be rare.

We tested 118 anti-snRNP sera for the presence of antisnRNA antibodies and found them in 45 sera (38\%). In all sera the antibodies (IgG and $F(a b)_{2}$ fragments thereof) were exclusively directed against $\mathrm{U} 1$ snRNA.

The anti-(U1)RNA antibodies were always accompanied by anti-(U1)RNP antibodies but were not found in sera which contain antibodies of the Sm serotype directed against all nucleoplasmic U snRNP particles. Like anti-RNP antibodies, anti-U1 RNA activity is confined to sera from patients with SLE or SLE overlap syndromes and is rarely found in patients with other connective tissue diseases.

By analyzing binding to subfragments of U1 snRNA made in vitro, it was demonstrated that anti-(U1)RNA antibodies recognize epitopes distributed throughout the U1 RNA molecule. In most sera, however, either the second or the fourth hairpin loop is the main target of the antibody.

The possible mechanisms that could lead to the production of this new type of autoantibody are discussed. (J. Clin. Invest. 1990. 86:2154-2160.) Key words: autoantibody • autoantigen • autoimmunity • small nuclear RNA • small nuclear ribonucleoprotein • U1 RNA

\section{Introduction}

Sera from patients with connective tissue diseases often contain antibodies against cellular components consisting of proteins associated with small RNA molecules of 80-200 nucleotides in length (reviewed in references 1 and 2). Autoantibodies against the nuclear type of these small RNA-protein complexes, the small nuclear ribonucleoproteins ( $\mathrm{snRNS}^{1}$ are mostly found in sera from patients with systemic lupus erythematosus (SLE) or SLE-overlap syndromes and several spec-

Address reprint requests to Dr. van Venrooij, Department of Biochemistry, University of Nijmegen, P.O. Box $9101,6500 \mathrm{HB}$ Nijmegen, The Netherlands.

Received for publication 23 February 1990 and in revised form 9 July 1990.

1. Abbreviations used in this paper: CIE, counterimmunoelectrophoresis; IB, immunoblotting; SLE, systemic lupus erythematosus; snRNP, small nuclear ribonucleoprotein.

J. Clin. Invest.

(C) The American Society for Clinical Investigation, Inc. 0021-9738/90/12/2154/07 \$2.00

Volume 86, December 1990, 2154-2160 ificities have been described. There are antibodies that precipitate U1 snRNPs only, in that they recognize one or more of the U1 snRNP-specific proteins $70 \mathrm{~mol}$ wt (70K), A, and C. These autoantibodies are most common in SLE-overlap patients but can be found in SLE patients as well (2). The second specificity, anti-Sm, precipitates all the major nucleoplasmic snRNPs since these antibodies recognize the proteins $B^{\prime} / B$ and $D$, which are common to these snRNPs. Anti-Sm antibodies are almost exclusively found in SLE patients. Immunoprecipitation studies, however, have established that anti-(U1)RNP antibodies are often accompanied by (mostly) low titers of antiSm antibodies (the so-called anti-RNP/Sm sera) (2).

A third, less common, specificity termed anti(U1,U2)RNP has been found in both SLE and SLE-overlap patients. These antibodies are in most cases directed against the U1-A and the U2-B" proteins but sometimes against the $\mathrm{U} 2-\mathrm{A}^{\prime}$ protein as well (2).

In all these cases the antibodies in the patients sera are directed against proteins contained in the snRNP particles. Antibodies against the (U)RNA components of snRNPs are thought to be rare $(1,3)$ although anti-RNA antibodies in autoimmune mice as well as in patients have been described (4-6).

In 1986, Wilusz and Keene (7) described the presence of anti-(U1)RNA autoantibodies in two anti-RNP sera. No general conclusions regarding an association between anti-RNP and/or Sm activity and anti-(U1)RNA activity could be drawn. The part of the U1 RNA recognized by one of these sera was mapped and found to include the second stem-loop of the RNA (8). By competition studies, it was shown that the binding of U1 RNA to the antibody was specific.

Since such anti-RNA antibodies can potentially be very useful for studies of RNA-protein interaction and may also teach us more about the phenomenon of autoantibody production and regulation of autoimmune processes, we started a study in which we tested a large number of anti-snRNP sera for the presence of anti-(U1)RNA antibodies. To our surprise we found them to be quite common. The antibodies were always directed against U1 snRNA. Using deletion mutants of Xenopus laevis U1 snRNA and in vitro-made stem-loops of U1 RNA, we show that several classes of antibodies that can bind to all four individual stem-loops of the U1 RNA molecule can be discerned.

\section{Methods}

Patient sera. Clinical characteristics and sera were collected from patients seen at the Departments of Rheumatology and Internal Medicine of the St. Radboud Hospital and of the St. Maartenskliniek, Nijmegen, The Netherlands. Diagnoses were obtained following published criteria essentially as described by de Rooij et al. (9).

Antibody profiles of sera were determined by counterimmunoelectrophoresis (CIE, 10), RNA precipitation (11), and immunoblotting (IB, 12).

Cells, labeling, and immunoprecipitation of RNP and RNA. HeLa cells were grown in suspension and monolayer culture as described 


\begin{tabular}{lllll}
\hline Serum antibody against & $n$ & CIE pattern & IB & RNP \\
immunoprecipitation & U1 \\
U1 RNP & 60 & RNP & 70K, A, or C & U1-U6 \\
Sm & 18 & Sm & B'/B and D & U1 (strong) \\
RNP/Sm & 25 & RNP (13) & 70K, A or C, and B'/B/D & U2-U6 (weak) \\
(U1, U2)RNP & 15 & RNP/Sm (12) & & U1, U2 \\
\end{tabular}

(13). For immunoprecipitation of snRNP complexes, extracts from cells labeled with ${ }^{32} \mathrm{PO}_{4}$ were prepared as described by Habets et al. (11). Immunoprecipitation was carried out in immunoprecipitation buffer ( $500 \mathrm{mM} \mathrm{NaCl}, 10 \mathrm{mM}$ Tris, pH 7.5, 0.05\% Nonidet P40) using the procedure described earlier (11).

In vivo-labeled RNA to be used in immunoprecipitation was isolated from cell extracts using the hot phenol method $\left(55^{\circ} \mathrm{C}\right.$, see van Eekelen and van Venrooij [13]). The purified RNA was then treated with pronase $\left(50 \mu \mathrm{g} / \mathrm{ml}\right.$ for $30 \mathrm{~min}$ at $\left.37^{\circ} \mathrm{C}\right)$, extracted again with phenol at $55^{\circ} \mathrm{C}$, and then precipitated with ethanol. The immunoprecipitation of naked RNA was carried out in the same way and under the same conditions as described above for RNP complexes. $10 \mu \mathrm{l}$ of serum per immunoprecipitation was used. Immunoprecipitated RNAs were analyzed on $10 \%$ acrylamide/urea gels (11).

Preparation of $I g G$ and $F(a b)_{2}$ fragments. IgG from human sera was isolated using protein A-Sepharose (Pharmacia, Uppsala, Sweden) and $0.1 \mathrm{M}$ glycine ( $\mathrm{pH} 2.5$ ) as eluent (14). $\mathrm{F}(\mathrm{ab})_{2}$ fragments were isolated by pepsin digestion of the IgG (14) and removal of the Fc fragments by binding to protein A-Sepharose. The binding of the $F(a b)_{2}$ fragments to protein A-Sepharose for immunoprecipitation was performed indirectly using a rabbit anti-human- $\lambda$ and $\kappa$-chain antibody (Dakopatts) bound to protein A-Sepharose. Thereafter, a standard immunoprecipitation was carried out.

RNA and RNA mutants made by T7 RNA synthesis. For T7 transcription, T7-(U1)DNA (15) was linearized with Bam H1, T7-(U2)DNA (16) was linearized with HindIII, and hY1 DNA, a kind gift of R. Slobbe, University of Nijmegen (for a review, see reference 17), was linearized with HindIII. The in vitro T7 RNA transcription was performed as follows. $2 \mu \mathrm{g}$ of linearized DNA was incubated in a total volume of $20 \mu$ l containing $40 \mathrm{mM}$ Tris $\cdot \mathrm{HCl}, \mathrm{pH} \mathrm{7.5,6} \mathrm{mM}$ $\mathrm{MgCl}_{2}, 2 \mathrm{mM}$ spermidine, $10 \mathrm{mM}$ DTT, $5 \mu \mathrm{g} \mathrm{BSA}, 0.5 \mathrm{mM}$ ATP, UTP, CTP/1 $\mu$ M GTP, 20 U RNase inhibitor (RNasin, Promega Biotec, Madison, WI), $0.05 \mathrm{mM} \mathrm{GpppG,} 15 \mathrm{U}$ T7 RNA polymerase (Promega Biotec) at $37^{\circ} \mathrm{C}$ for $1 \mathrm{~h}$ in the presence of $4 \mu \mathrm{Ci}\left[\alpha-{ }^{32} \mathrm{P}\right] \mathrm{GTP}$ $(3,000 \mathrm{Ci} / \mathrm{mmol})$. After transcription, DNase I $(2 \mu \mathrm{g})$ and $\mathrm{CaCl}_{2}$ (final concentration $50 \mathrm{mM}$ ) were added and incubation was continued for $15 \mathrm{~min}$ at $37^{\circ} \mathrm{C}$. Finally $180 \mu \mathrm{l}$ of TE buffer $(10 \mathrm{mM}$ Tris $\cdot \mathrm{HCl}, \mathrm{pH} 7.5$, 1 mM EDTA) was added, the RNA was phenol extracted, purified over

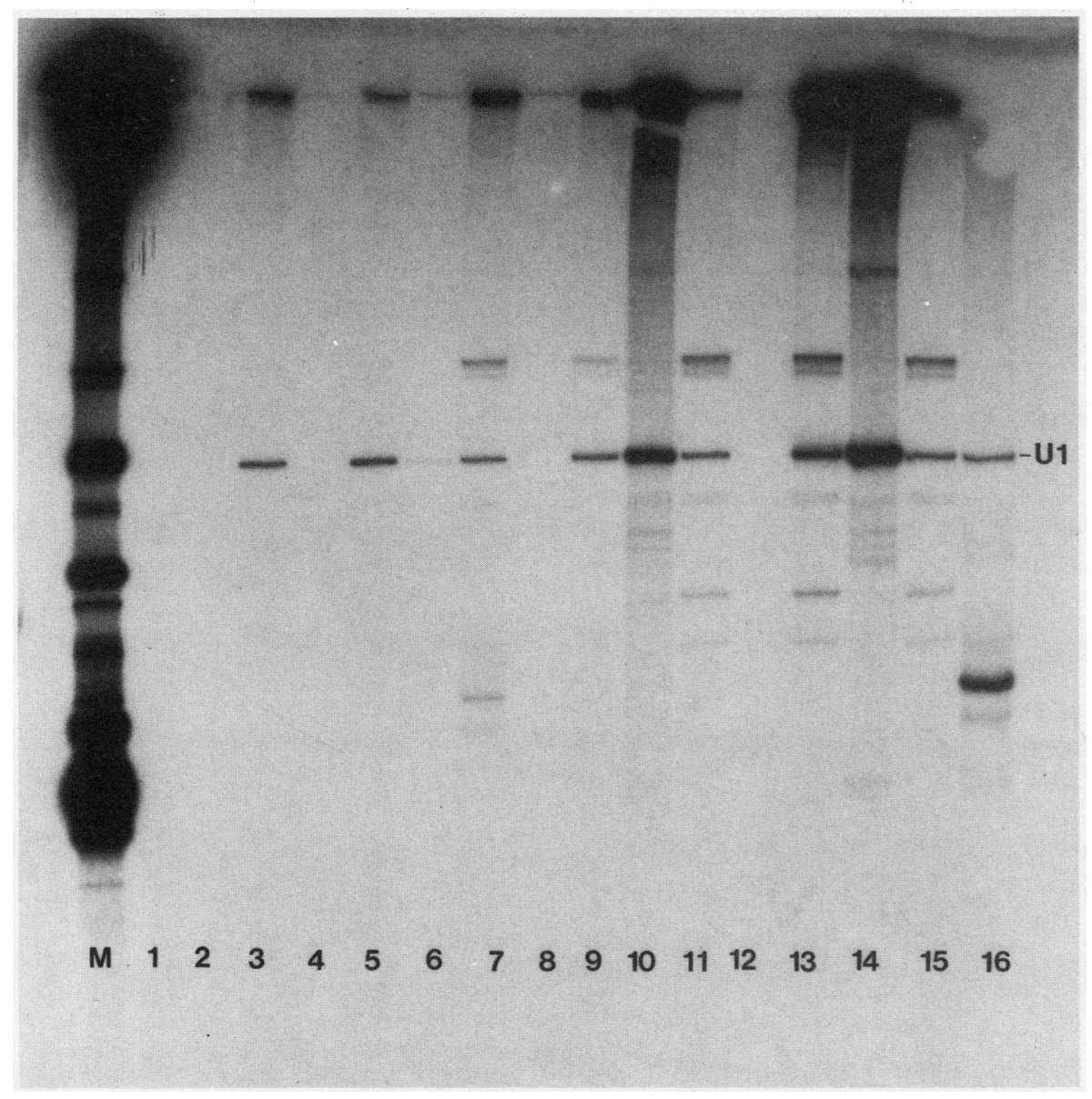

Figure 1. RNP and RNA immunoprecipitation with various patient sera. Immunoprecipitation of RNP complexes (odd numbered lanes) was carried out using a ${ }^{32} \mathrm{P}$-labeled extract from HeLa cells. The RNA moiety of the immunoprecipitates was subsequently analyzed as described in Methods. Immunoprecipitation of naked in vivo labeled RNA (even numbered lanes) and analysis of the immunoprecipitated RNAs was carried out as described (11). Lanes 1, 2, normal human serum; lanes 3, 4, serum S037, anti-(U1)RNP serum, no anti-RNA antibodies; lanes 5, 6, serum B175, anti-(U1)RNP, anti-(U1)RNA serum; lanes 7,8 , serum B025, anti-(U1,U2)RNP, anti-La, no anti-RNA antibodies; lanes 9,10 , serum D086, anti-(U1,U2)RNP, anti-(U1)RNA serum; lanes 11, 12, serum C045, anti-Sm serum, no anti-RNA antibodies; lanes 13 , 14, serum M078, anti-RNP/Sm serum, anti-(U1)RNA activity; lanes 15,16 , serum B156, anti-RNP/Sm serum, anti-(U1)RNA activity. Note that serum B156 (lane 16) precipitates another naked RNA, somewhat smaller than U6 snRNA. The U1 RNA band in lane 6 is very faint and may not show up after reproduction. 
Table II. Anti-(UI)RNA Activity in Human Anti-snRNP Antisera

\begin{tabular}{lcc}
\hline $\begin{array}{c}\text { Serum } \\
\text { antibody against }\end{array}$ & $n$ & $\begin{array}{c}\text { Anti-(U1)RNA } \\
n(\%)\end{array}$ \\
\hline U1 RNP & 60 & $24(40)$ \\
(U1, U2)RNP & 15 & $8(53)$ \\
RNP/Sm & 25 & $13(52)$ \\
Sm & 18 & $0(0)$
\end{tabular}

a G-50 spin column, and, after addition of carrier yeast tRNA, precipitated with 3 vol ethanol/0.1 vol $3 \mathrm{M} \mathrm{Na}$-acetate, $\mathrm{pH} 5.2$. The in vitromade RNA was analyzed on a nondenaturing gel and was found to be monomeric U1, U2 or hY1 RNA.

The mutated Xenopus laevis U1 RNAs (see Fig. 4) were constructed as described previously (15). Each of the three stem-loop structures at the $5^{\prime}$ end of the U1 molecule was deleted separately giving rise to mutants $\Delta \mathrm{A}, \Delta \mathrm{B}$, and $\Delta \mathrm{C}$, respectively. The potential Sm binding site was substituted (mutant $\Delta \mathrm{D}$ ) or the $3^{\prime}$-most stem-loop was reduced in size while the sequence found conserved in this loop (18) was altered (mutant $\Delta \mathrm{E}$ ). The predicted secondary structure of U1
RNA as deduced from phylogenetic evidence (19-21) and the structures of the mutant RNAs derived from it are shown in Fig. 4.

For transcription of the first stem-loop, Xenopus U1 DNA was linearized after nucleotide 58 with Dde I. Subsequent transcription yields an RNA covering stem-loop I plus an additional 10 nucleotides at the $3^{\prime}$ end.

For transcription of the third stem-loop Xenopus U1 DNA was digested with Hpa II and Taq I. The 42-bp (nucleotides 73-115) fragment covering $18 \mathrm{bp}$ of the $3^{\prime}$ end of the second stem-loop plus the greater part of the third stem-loop was ligated into the Acc I site of the polylinker region of the PGEM-3Zf $(+)$ vector. For transcription the vector was digested with Pst I and then treated with Klenow DNA polymerase to convert the $3^{\prime}$ overhang into a blunt end.

\section{Results}

Anti-(U1)RNA activities are often present in anti-RNP sera. We identified, via screening with CIE and IB, 118 sera that contained anti-snRNP activity. After RNP immunoprecipitation, 60 sera were classified as anti-(U1)RNP and 18 sera as anti-Sm. 25 sera contained anti-RNP as well as anti-Sm anti-

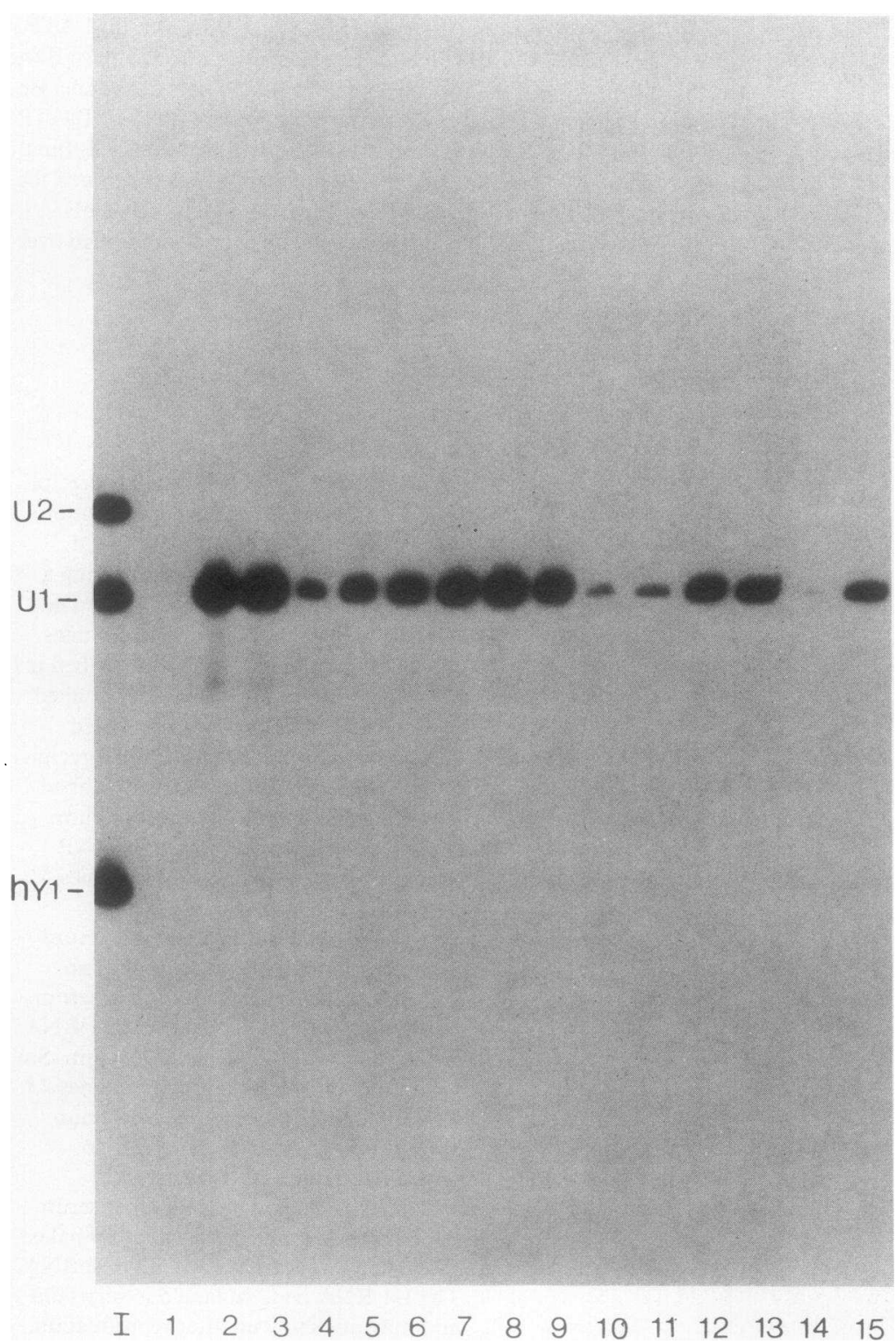

Figure 2. Precipitation of in vitro-made U1 RNA from Xenopus laevis by human antibodies. $\mathrm{U} 1$ and $\mathrm{U} 2 \mathrm{sn}-$ RNA from Xenopus laevis as well as human Y1 RNA from HeLa cells (15-17) were transcribed in vitro using T7 RNA polymerase (see Methods). The RNAs were radiolabeled with $\left[\alpha-{ }^{32}\right.$ P]GTP and deproteinized by phenol treatment. IgG from control and patient sera were bound to protein A-Sepharose and incubated with a mixture of the three in vitro-made RNAs in IPP (11). The precipitated RNAs were separated by acrylamide-urea gel electrophoresis (11). I, $10 \%$ of the input RNA mixture; lane 1 , control human serum; lanes $2-15$, patients sera with anti-(U1)RNA antibodies. 
bodies while 15 sera exhibited anti-(U1,U2)RNP activity (Table I). These 118 sera were all tested for their ability to precipitate deproteinized U snRNAs. For this purpose total ${ }^{32} \mathrm{P}$-labeled HeLa cell RNA, purified by extensive pronase and phenol/detergent treatment (see Methods), was used as antigen in the precipitation assay. Some typical examples of the observed precipitation patterns are depicted in Fig. 1.

The overall results (Table II) show that 45 of the 118 sera contained anti-(U1)snRNA antibodies. In some cases additional antibodies against 5.8S RNA or tRNA were observed as well, but no antibody against one of the other abundant snRNAs could be detected. Most surprising was the finding that anti-(U1)RNA activity was not found in any of the Sm sera tested (Table II). We calculated the efficiency of precipitation and found that generally between $10 \%$ and $30 \%$ of the U1 RNA input was precipitated. This was the case either when the immunoprecipitation was carried out at high $(500 \mathrm{mM})$ or physiological $(150 \mathrm{mM}) \mathrm{NaCl}$ concentrations. The fact that not all input RNA was precipitated probably reflects the equilibrium between Ig-RNA complexes and free RNA molecules.

The anti-(U1)RNA antibodies were detected only in antiRNP sera and such antibodies are primarily present in SLE and SLE overlap patients. When the presence of anti-(U1)RNA antibodies was correlated with the clinical diagnosis they were found in $\sim 30 \%$ of the anti-snRNP positive sera from patients with SLE and in about $60 \%$ of the anti-snRNP positive sera from patients with SLE-overlap disease. In sera from patients with other connective tissue diseases which also contained anti-snRNP antibodies, the anti(U1)RNA antibodies were only detected in a few cases (data not shown).

Patient serum, IgG, and $F(a b)_{2}$ fragments precipitate in vitro-made U1 RNA. To establish the specificity of the antibody reaction with (U1)RNA more rigorously, DNA coding for some small RNAs (Xenopus laevis U1 RNA, Xenopus laevis U2 RNA, and human hYRNA-1) were transcribed in vitro using T7 RNA polymerase. These in vitro-made RNAs, radiolabeled with $\left[\alpha_{-}{ }^{32} \mathrm{P}\right] \mathrm{GTP}$ and deproteinized by phenol treatment, were then incubated with protein A-Sepharose bound antibodies from a number of sera. The antibody-bound RNAs were analyzed by polyacrylamide-urea gel electrophoresis. The results show that all sera recognized U1 RNA only (Fig. 2). This result also indicates that the modified nucleotides which are present in the in vivo-made UI RNA are not the main targets of the antibodies. In some comparative studies we used a human U1 snRNA produced in vitro and this RNA was precipitated with the same efficiency as the Xenopus RNA (data not shown). To unequivocally show that IgG antibodies recognize the U1 RNA molecules, the same type of experiment was repeated using purified $\operatorname{IgG}$ and $F(a b)_{2}$ fragments. The results shown in Fig. 3 clearly indicate that both the IgG and the $F(a b)_{2}$ fragments of the patient sera precipitate $U 1$ RNA out of the mixture of labeled RNAs presented to them. The control human serum, IgG, and $F(a b)_{2}$ fragments did not precipitate any labeled RNA (Fig. 3, lanes 7-9).

The anti-(U1)RNA activity can be directed against every individual stem-loop of the RNA. The results obtained so far indicated that U1 snRNA is the only snRNA recognized by these sera. Deutscher and Keene (8) found that one of their anti-(U1)RNA sera recognized the greater part of the second stem-loop. To learn more about the RNA epitope regions rec-

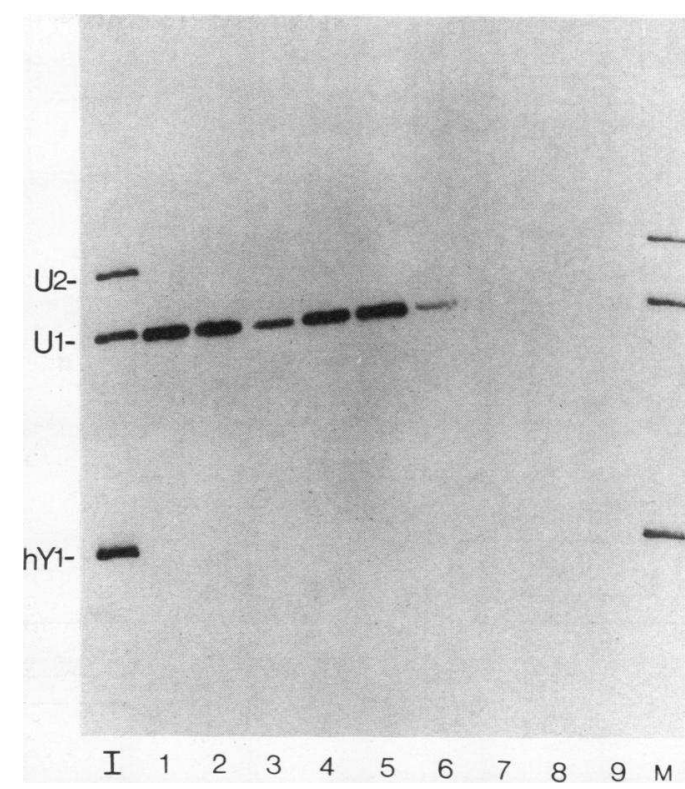

Figure 3. Precipitation of U1 RNA by serum, $\mathrm{IgG}$, and $\mathrm{F}(\mathrm{ab})_{2}$ fragments. U1, U2, and hY1 RNA were made in vitro and purified as described in the legend of Fig. 2. The mixture of RNAs was then incubated with either protein A-Sepharose-bound antibodies or with IgG purified from the serum or with $\mathrm{F}(\mathrm{ab})_{2}$ purified from the IgG (see Methods). The RNA-antibody complexes were recovered as described in Methods and the precipitated RNAs were separated by acrylamide-urea electrophoresis. I, 10\% of input RNA mixture; lanes 1 and 4, 2 and 5, 3 and 6 show the U1 RNA precipitated by the serum, IgG and $F(a b)_{2}$ fragments, respectively, of two patients sera with anti-(U1)RNA antibodies. Lanes 7,8 , and 9 show the patterns of the control serum, IgG, and $\mathrm{F}(\mathrm{ab})_{2}$ fragments, respectively. $M$, Marker input RNAs.

ognized by the antibodies in our sera we decided to use a number of deletion mutants of the Xenopus U1 snRNA gene used in earlier studies (15). Fig. 4 gives an overview of the secondary structures of these mutants.

About equal amounts of the radiolabeled wild-type (U1)snRNA and the mutants $\Delta \mathrm{A}, \Delta \mathrm{B}, \Delta \mathrm{C}, \Delta \mathrm{D}$, and $\Delta \mathrm{E}$ were used in the precipitation assay that was carried out in the presence of $500 \mathrm{mM} \mathrm{NaCl}$. We tested 26 sera and obtained three types of precipitation patterns.

Six sera (23\%) precipitated the wild-type RNA and all mutants except $\triangle B$, indicating that these sera have only antibodies recognizing the second stem-loop (Fig. $5 A$ ).

Four sera $(15 \%)$ precipitated the wild-type RNA and all mutants except $\Delta \mathrm{E}$, indicating that in these sera the top of stem-loop IV forms the epitope (Fig. $5 \mathrm{~B}$ ). The other sera precipitated all mutant RNAs (Fig. $5 C$ ). This precipitation behavior can be explained by assuming that in these sera a mixture of antibodies, directed against more than one RNA epitope, is present.

These results show that the anti-RNA antibodies can at least be directed against either stem-loop II or IV. To investigate whether antibodies against the two other stem-loops can be present in human sera, we performed immunoprecipitation with substrates containing only either stem-loop I or stem-loop III. The RNAs were prepared as described in Methods and the precipitation was performed in the presence of wild-type U1 RNA as an internal control. A selection of the immunoprecip- 

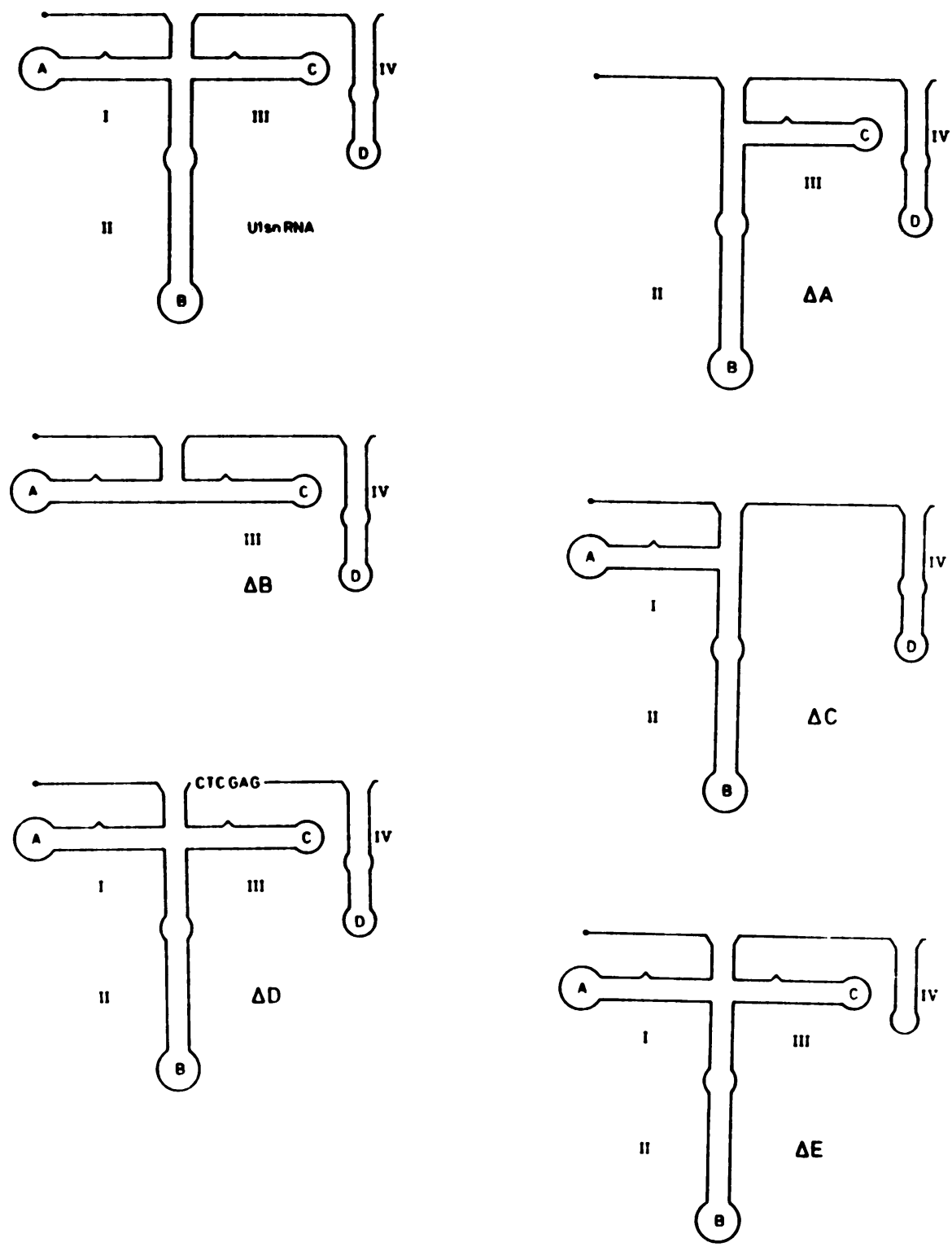

Figure 4. Possible secondary structures of wild-type Xenopus laevis U1 snRNA and U1 RNA mutants. Deletions and substitutions were introduced into a $X$. leavis $\mathrm{U} 1$ RNA gene as described (15). Mutants are: $(A)$ deletion of $\mathrm{nt} 18-48 ;(B)$ deletion of $\mathrm{nt}$ 51-92; $(C)$ deletion of nt 93-118; (D) substitution of nt 125-130 (TAATTT to CTCGAG); $(E)$ deletion of nt 145-149 and $154-158$ and substitution of $n t$ 150-153 (TTCG to AGAA). itation data is shown in Fig. 6.2 of 15 sera tested had antistem-loop I activity (Fig. $6 \mathrm{~A}$, lane 4 ) whereas 3 from 15 had anti-stem-loop III activity (Fig. $6 B$, lanes 3 and 4). However, all these sera also contained antibodies against either stemloop II or stem-loop IV (data not shown). These results indicate that antibodies against all four stem-loops present in U1 RNA can be detected in human autoimmune sera.

\section{Discussion}

In this study we have shown that in about $45 \%$ of human anti-RNP sera (i.e., anti-(U1)RNP, anti-(U1,U2)RNP, or anti-RNP/Sm) antibodies directed against the U1 RNA component can be found and that these antibodies are either absent or rarely present in anti-Sm sera (Table II). This type of antibody is therefore much more common than previously believed $(1,3,7)$. The antibodies are sometimes directed against one stem-loop only (23\% against stem-loop II, $15 \%$ against stem-loop IV), but in more complex sera antibodies against the other RNA epitopes were also found. By using purified IgG and $\mathrm{F}(\mathrm{ab})_{2}$ fragments and by immunoprecipitating U1 RNA from a mixture of either total cellular RNA or of three different in vitro-made RNAs, we established that the phenomenon studied was indeed a specific reaction between patient Ig and U1 RNA.

In this study we chose to use mutants in which individual and complete structural elements, based on strong phylogenetic evidence (19-21), were deleted because that would create the least possible change in the tertiary structure of the RNA. The previously observed stability of these mutant RNAs in vivo $(15,22)$ strongly supports the fact that the predicted mutant RNA structures are likely to be correct. Our results also support this view because antibodies directed against a particular stem-loop in U1 RNA always, with comparable efficiency, recognized the mutants in which this epitopic stem-loop was present. Furthermore, stem-loops I and III were prepared individually and shown also to be specific antigens (see Figs. 5 and 6). Recently, we have also prepared stem-loops II and IV and 

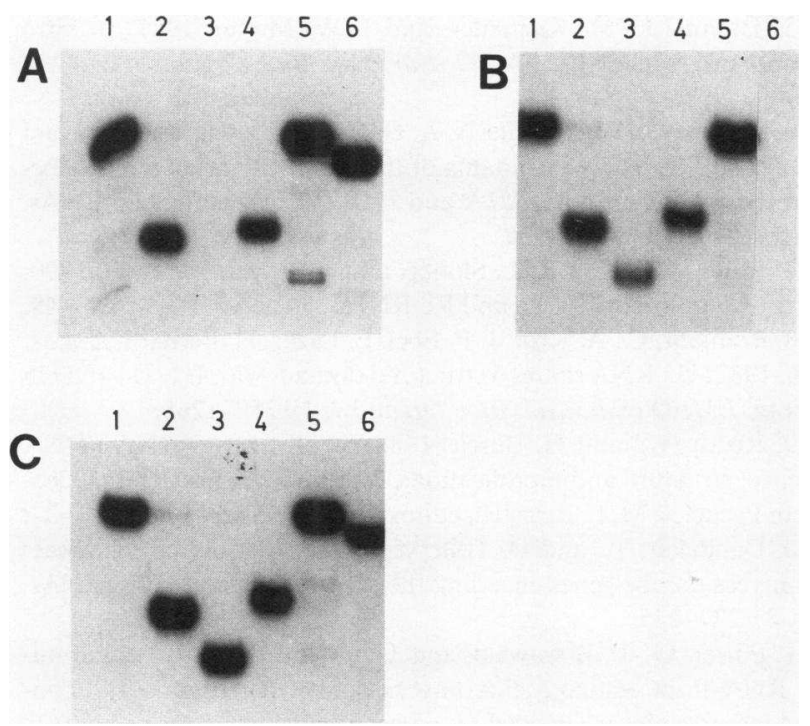

Figure 5. Immunoprecipitation of U1 snRNA and U1 snRNA mutants by different patient sera. Immunoprecipitation was carried out using $X$. laevis U1 RNA (lanes 1$)$, as well as several mutants $(\Delta A$, lanes $2 ; \Delta \mathrm{B}$, lanes $3 ; \Delta \mathrm{C}$, lanes $4 ; \Delta \mathrm{D}$, lanes 5 ; and $\Delta \mathrm{E}$, lanes 6$)$ as the antigen. $(A)$ Anti-(U1)RNP serum D004; (B) anti-(U1)RNP serum S003; (C) anti-(U1)RNP serum E033.

could show that antibodies specifically reacting with these domains of U1 RNA also reacted with the individual in vitromade stem-loops (data not shown).

How do these antibodies arise? Presentation of naked U1 RNA to the immune system seems unlikely because RNA is rarely naked in vivo and would be degraded very rapidly due to ribonucleases in the blood. Another possibility is that the antibodies are generated in the patient by another RNA not present in HeLa cells and coincidently cross-react with human U1 RNA. Several authors have shown the presence of anti-RNA antibodies in SLE sera. These antibodies can be directed against ssRNA, dsRNA, GC-rich RNAs, and viral RNAs (4-6). However, U1 and U2 RNA have about similar structures and also the loops of U1 RNA are not more guanosine/ cytosine-rich than the loops in U2 RNA. Nevertheless, U2
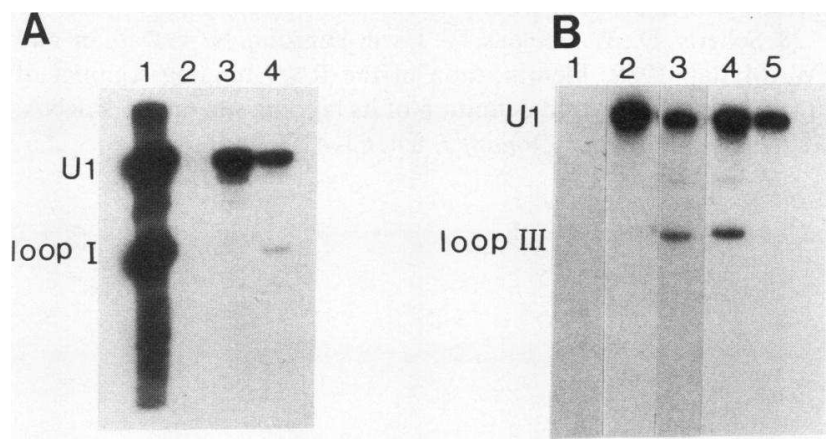

Figure 6. Immunoprecipitation of U1 snRNA and in vitro synthesized stem-loop I and stem-loop III RNA. Immunoprecipitation was carried out as described in Methods. ( $A$ ) Lane 1 , input RNA (U1 and stem-loop I RNA); lane 2, control normal human serum; lane 3, anti-(U1)RNP serum B152; lane 4, anti-(U1)RNP serum B156. (B) Lane 1, control normal human serum; lanes 2 and 5, anti-(U1)RNP sera T040 and B152; lanes 3 and 4, anti-(U1)RNP serum M078 and anti-(U1,U2)RNP serum P028, respectively.
RNA is not recognized by these antibodies. Our results suggest that we are dealing with a hitherto undetected class of antiRNA antibodies.

Another argument supporting the idea that these antibodies do not recognize U1 RNA by chance cross-reaction, but have indeed been generated against human U1 RNA, is the fact that no antibodies against other major snRNAs (e.g., U2, U4, U5 or U6) were detectable. The second loop of U1 RNA which is recognized by the majority of the anti-U1 RNA antibodies differs in only a few nucleotides from the fourth loop of U2 RNA (16). Nevertheless, U2 RNA is not precipitated by the human antibodies. The secondary (19) and possibly the tertiary structures (23) of the (U)RNAs are very similar but no antibodies against (U)RNAs other than U1 could be found. Strong anti-RNP/Sm sera that precipitated the abundant (U1-U6)RNPs were found to have an anti-RNA specificity directed only against U1 RNA. Finally, the fact that many sera contain antibodies which recognize more than one epitope on U1 snRNA argues very strongly that $\mathrm{U} 1$ itself is the antigen which has elicited the immune response. The finding that anti-Sm sera with high titer antibodies against U1-U6 snRNPs did not precipitate naked RNA at all is puzzling. Obviously, the anti-(U1)RNA specificity is somehow associated with anti-(U1)RNP activity although a clear correlation between the titer of the anti-RNP activity and the presence of anti-(U1)RNA antibody was not found (data not shown).

Anti-(U1)RNP antibodies are always directed against one or more of the specific proteins U1-70K, U1-A, or U1-C (2). The $70 \mathrm{~K}$ and $C$ proteins are associated with the first stem-loop of U1 RNA $(15,22,24,25)$ and the A protein is bound to the second stem-loop $(16,26-28)$. Therefore, it could be argued that the anti-(U1)RNA antibodies might be anti-idiotypes of those anti-(U1)RNP antibodies that are directed against the RNA binding sites of the specific proteins. However, sera with specificity against stem-loop IV, a loop of the U1 RNA not known to be associated with protein $(15,22,24-28)$, were often found. Furthermore, antibody against the U1-A protein is found in $>90 \%$ of the anti-(U1)RNP sera, thus also in sera containing no anti-(U1)RNA antibodies or in sera containing antibodies recognizing parts of U1 RNA other than the second stem-loop. Although the finding that sera can contain several different anti-(U1)RNA antibodies argues against it being the sole mechanism for generating the anti-RNA activity, the possibility that some anti-(U1)RNA antibodies might be antiidiotypic deserves further study.

The question of why no antibodies against the other $U$ RNAs (in particular U2) are found, remains. These RNAs are also associated with antigens, and it is not clear why in these cases a putative anti-idiotypic response is not observed.

Our further studies will be directed to a more detailed mapping of the regions and sequences in U1 RNA recognized by the human autoantibodies as well as sequential antibody measurements and temporal analysis of these determinations relative to disease onset because such knowledge may have important theoretical implications for the understanding of the disease.

\section{Acknowledgments}

We would like to thank Dr. R. Slobbe for giving us the hY1 RNA clone and Dr. W. J. Habets and Dr. W. Boelens for helpful discussions.

This work was financially supported in part by grants from the 
Netherlands League against Rheumatism, Organon Teknika, and The Netherlands Organization for Scientific Research (NWO/STW, grant NBI 88-1466).

\section{References}

1. Tan, E. M. 1989. Antinuclear antibodies: diagnostic markers for autoimmune diseases and probes for cell biology. Adv. Immunol. 44:93-152.

2. Van Venrooij, W. J., and P. T. G. Sillekens. 1989. Small nuclear RNA associated proteins: autoantigens in connective tissue diseases. Clin. Exp. Rheumatol. 7:635-645.

3. Chan, E. K. L., and E. M. Tan. 1989. Epitopic targets for autoantibodies in systemic lupus erythematosus and Sjögren's syndrome. Curr. Opin. Rheumatol. 1:376-381.

4. Eilat, D., M. Hochberg, R. Fischel, and R. Laskov. 1982. Antibodies to RNA from autoimmune NZB/NZW mice recognize a similar antigenic determinant and show a large idiotypic diversity. Proc. Natl. Acad. Sci. USA. 79:3818-3822.

5. Eilat, D., A. D. Steinberg, and A. N. Schechter. 1978. The reaction of SLE antibodies with native, single stranded RNA: radioassay and binding specificities. J. Immunol. 120:550-557.

6. Spencer-Green, G., L. Kelley, L. E. Adams, R. Donovan-Brand, and E. V. Hess. 1986. Polynucleotide antibodies in connective tissue disease: viral markers or disease mediators. J. Lab. Clin. Med. 107:159-165.

7. Wilusz, J., and J. D. Keene. 1986. Autoantibodies specific for U1 RNA and initiator methionine tRNA. J. Biol. Chem. 261:5467-5472.

8. Deutscher, S. L., and J. D. Keene. 1988. A sequence-specific conformational epitope on U1 RNA is recognized by a unique autoantibody. Proc. Natl. Acad. Sci. USA. 85:3299-3304.

9. de Rooij, D. J., L. B. van de Putte, W. J. Habets, A. L. Verbeek, and W. J. van Venrooij. 1988. The use of immunoblotting to detect antibodies to nuclear and cytoplasmic antigens. Scand. J. Rheumatol. 17:353-364.

10. Kurata, N., and E. M. Tan. 1976. Identification of antibodies to nuclear acidic antigens by counterimmunoelectrophoresis. Arthritis Rheum. 19:574-581.

11. Habets, W., M. Hoet, P. Bringmann, R. Lührmann, and W. van Venrooij. 1985. Autoantibodies to ribonucleoprotein particles containing U2 small nuclear RNA. EMBO (Eur. Mol. Biol. Organ.) J. 4:1545-1550.

12. Habets, W. J., D. J. de Rooij, M. H. Hoet, L. B. van de Putte, and W. J. van Venrooij. 1985. Quantitation of anti-RNP and anti-Sm antibodies in MCTD and SLE patients by immunoblotting. Clin. Exp. Immunol. 59:457-466.

13. van Eekelen, C. A., and W. J. van Venrooij. 1981. HnRNA and its attachment to a nuclear protein matrix. J. Cell Biol. 88:554-563.

14. Harlow, E., and D. Lane. 1988. Antibodies, A Laboratory Manual. Cold Spring Harbor Laboratory, Cold Spring Harbor, NY. 725 pp.
15. Hamm, J., M. Kazmaier, and I. W. Mattaj. 1987. In vitro assembly of U1 snRNPs. EMBO (Eur. Mol. Biol. Organ.) J. 6:34793485 .

16. Scherly, D., W. Boelens, N. A. Dathan, W. J. van Venrooij, and I. W. Mattaj. 1990. Determinants of the specificity of interaction between the snRNP proteins U1A and U2B" and their cognate RNAs. Nature (Lond.). 345:502-506.

17. Pruyn, G. J. M., R. L. Slobbe, and W. J. van Venrooij. 1990. Structure and function of La and Ro RNPs. Mol. Biol. Rep. 14:43-48.

18. Branlant, C., A. Krol, J. P. Ebel, E. Lazar, H. Bernard, and M. Jacob. 1982. U2 RNA shares a structural domain with U1, U4 and U5 snRNAs. EMBO (Eur. Mol. Biol. Organ.) J. 1:1259-1265.

19. Reddy, R., and H. Busch. 1988. Small nuclear RNAs: RNA sequence, structure and modifications. In Small Nuclear Ribonucleoprotein Particles. M. L. Birnstiel, editor. Springer-Verlag, Berlin. 1-37.

20. Dandekar, T., and D. Tollervey. 1989. Cloning of Schizosaccharomyces pombe genes encoding the U1, U2, U3 and U4 snRNAs. Gene. 81:227-235.

21. Porter, G., P. Bremwald, and J.-A. Wise. 1990. U1 small nuclear RNA from Schizosaccharomyces pombe has unique and conserved features and is encoded by an essential single copy gene. $\mathrm{Mol}$. Cell. Biol. 10:2874-2881.

22. Hamm, J., N. A. Dathan, D. Scherly, and I. W. Mattaj. 1990. Multiple domains of U1 snRNA including U1 specific protein binding sites are required for splicing. EMBO (Eur. Mol. Biol. Organ.) J. 9:1237-1244.

23. Kastner, B., M. Bach, and R. Lührmann. 1990. Electron microscopy of small nuclear ribonucleoprotein (snRNP) particles U2 and U5: evidence for a common structure-determining principle in the major U snRNP family. Proc. Natl. Acad. Sci. USA. 87:1710-1714.

24. Query, C. C., R. C. Bentley, and J. D. Keene. 1989. A specific 31-nucleotide domain of U1 RNA directly interacts with the 70K small nuclear ribonucleoprotein component. Mol. Cell. Biol. 9:48724881 .

25. Surowy, C., V. L. van Santen, S. M. Scheib-Wixted, and R. A. Spritz. 1989. Direct, sequence-specific binding of the human U1-70K ribonucleoprotein antigen protein to loop I of U1 small nuclear RNA. Mol. Cell. Biol. 9:4179-4186.

26. Lutz-Freyermuth, C., and J. D. Keene. 1989. The U1 RNAbinding site of the U1 small nuclear ribonucleoprotein (snRNP)-associated A protein suggests a similarity with U2 snRNPs. Mol. Cell. Biol. 9:2975-2982.

27. Patton, J. R., W. Habets, W. J. van Venrooij, and T. Pederson. 1989. U1 small nuclear ribonucleoprotein particle-specific proteins interact with the first and second stem-loops of U1 RNA, with the A protein binding directly to the RNA independently of the $70 \mathrm{~K}$ and $\mathrm{Sm}$ proteins. Mol. Cell. Biol. 9:3360-3368.

28. Scherly, D., W. Boelens, W. J. van Venrooij, N. A. Dathan, and I. W. Mattaj. 1989. Identification of the RNA binding segment of human U1 A protein and definition of its binding site on U1 snRNA. EMBO (Eur. Mol. Biol. Organ.) J. 8:4163-4170. 